\title{
Um estudo de caso sobre a atuação inclusiva dos professores de audição e linguagem na Espanha
}

\begin{abstract}
A case study on inclusive practice of hearing and language teachers in Spain Un estudio de caso sobre la actuación inclusiva de los profesores de audición y lenguaje en España
\end{abstract}

\begin{abstract}
* Daiane Natalia Schiavon
Doutoranda pela Universidade Estadual Paulista (UNESP), São Paulo, São Paulo, Brasil. daia_schiavon@yahoo.com.br
\end{abstract}

\section{** Eladio Sebastian Heredero}

Professor doutor na Universidade de Alcalá, Guadalajara, Madrid, Espanha

eladio.sebastian@gmail.com

Recebido em 31 de outubro de 2016

Aprovado em 25 de outubro de 2017

\section{RESUMO}

Este estudo objetivou caracterizar o trabalho pedagógico do professor de Audição e Linguagem no sistema educativo espanhol (Guadalajara - Castilla-La Mancha). Constituiuse numa pesquisa de caráter qualitativo. Foi desenvolvida em uma escola Educação Infantil e Primária da cidade de Guadalajara, província de Castilla-La Mancha - Espanha, e participou deste estudo a professora de Audição e Linguagem deste centro. Foi utilizado como instrumentos de coleta de dados a observação do trabalho desta professora e entrevista realizada com a mesma. Os resultados abordaram os aspectos positivos do trabalho do professor de Audição e linguagem para o processo de ensino e aprendizagem de alunos com dificuldades comunicativas ocasionadas ou não por alguma deficiência, bem como a importância de uma formação docente adequada para atender as necessidades dos alunos frente à promoção das competências linguísticas. Destarte, apontaram ainda questões que permitiram diálogo e reflexões para o contexto brasileiro, no sentido de novas possibilidades para a educação no país.

Palavras-chave: Trabalho pedagógico; Professor de Audição; Linguagem; Inclusão.

\section{ABSTRACT}

This study aimed to characterize the pedagogical work of the teacher of Hearing and Language in the Spanish educational system (Guadalajara - Castilla-La Mancha). It constituted a qualitative research. It was developed in a childhood education school and Primary city of Guadalajara province of Castilla-La Mancha - Spain, and participated in this study Professor of Hearing and Language of this center. It used as instruments for data collection observation of the work of this teacher and interview with it. The results addressed 
the positive aspects of hearing and language teacher working for the teaching and learning process of students caused communication difficulties or not by a disability, as well as the importance of proper teacher training to meet the students' needs front promotion of language skills. Thus, even pointed questions that allow dialogue and reflections to the Brazilian context, in the sense of new possibilities for education in the country.

Keywords: Pedagogical work; Hearing teacher; Language; Inclusion.

\section{RESUMEN}

Este estudio objetivó caracterizar el trabajo pedagógico del profesor de Audición y Lenguaje en el sistema educativo español (Guadalajara - Castilla-La Mancha). Se constituyó en una investigación de carácter cualitativo. Fue desarrollada en una escuela Educación Infantil y Primaria de la ciudad de Guadalajara, provincia de Castilla-La Mancha - España, y participó de este estudio la profesora de Audición y Lenguaje de este centro. Se utilizó como instrumentos de recolección de datos la observación del trabajo de esta profesora y entrevista realizada con la misma. Los resultados abordaron los aspectos positivos del trabajo del profesor de Audición y lenguaje para el proceso de enseñanza y aprendizaje de alumnos con dificultades comunicativas ocasionadas o no por alguna deficiencia, así como la importancia de una formación docente adecuada para atender las necesidades de los alumnos frente a las necesidades de los alumnos, promoción de las competencias lingüísticas. De este modo, apuntaron aún cuestiones que permitieron diálogo y reflexiones para el contexto brasileño, en el sentido de nuevas posibilidades para la educación en el país.

Palabras clave: Trabajo pedagógico; Profesor de Audición; idioma; Inclusión.

\section{Introdução}

A atenção à diversidade no âmbito educativo tem seus antecedentes nos movimentos de normalização que surgem na década de 1970 do século passado nos países nórdicos europeus e nos Estados Unidos. Tal movimento pressupôs mudanças na concepção de pessoas com deficiência com a intenção de encontrar o melhor caminho para que estas pudessem se desenvolver em nível individual e social. Tomando como referência este marco educativo, os países passaram a incorporar progressivamente (uns antes que outros) políticas de inclusão escolar e a adotar assim, medidas e práticas mais inclusivas.

Dessa forma, destaca-se no contexto educativo espanhol (realidade objeto desta pesquisa) como uma destas medidas, o "Plan de Atención a la diversidad", que consiste em um conjunto de medidas desde a intervenção em um processo de ensino-aprendizagem normalizado até seu desenvolvimento em um marco especifico com um currículo adaptado. 
Este plano tem por finalidade, dar uma resposta, no âmbito educativo as diferentes capacidades e estilos de aprendizagem dos alunos matriculados na escola (CASTILLA-LA MANCHA, 2002).

Tal plano é um documento que aglutina o conjunto de atuações referentes às adaptações curriculares, as medidas organizativas e os apoios e reforços que a escola coloca em prática para proporcionar a resposta mais adequada às necessidades educativas, gerais e particulares, de todo o alunado. Neste sentido são realizadas avaliações com os alunos, a fim de diagnosticar suas necessidades e oferecer o tipo de atendimento mais adequado aos mesmos.

Inseridos nestes apoios e tipos de atendimento, além dos professores comuns (chamados "Tutores"), se encontram os professores de Pedagogia Terapêutica (PT) e de Audição e Linguagem (AL). O professor de Pedagogia Terapêutica é o especialista dedicado a promover o ensino aos alunos com necessidades associadas a deficiências ou a transtornos graves de conduta. Já o professor de Audição e Linguagem, sobre o qual nos centraremos neste trabalho, é um especialista dedicado a promover competências linguísticas, a desenvolver a prevenção dos problemas de linguagem e melhorar patologias relacionadas à linguagem oral e escrita (ESPANHA, 1995). Aqui destacaremos o trabalho do professo de Audição e Linguagem, objeto deste estudo.

O professor AL atua também em colaboração com os demais professores, intervindo de acordo com a seguinte ordem de prioridades:
a) La atención individualizada al alumnado con deficiencias auditivas significativas y muy significativas o con trastornos graves de la comunicación asociados a lesiones cerebrales o alteraciones de la personalidad.
b) La atención al alumnado con disfemias y dislalias orgánicas.
c) La realización de los procesos de estimulación y habilitación del alumnado en aquellos aspectos determinados en las correspondientes adaptaciones curriculares y en los programas de refuerzo y apoyo.
d) La orientación, en su caso, al profesorado de educación infantil en la programación, desarrollo y evaluación de programas de estimulación del lenguaje (CASTILLA-LA MANCHA, 2002, p.10876).

Destaca-se ainda que este professor pode realizar intervenções prioritariamente no último curso da educação infantil e no primeiro ciclo da educação primaria. Também é importante dizer que este professor pode atuar dentro ou fora da sala de aula e com um grupo de alunos ou mesmo individualmente.

Tendo em vista o papel importante que exerce o professor de Audição e Linguagem cabe a este fazer parte da equipe docente de orientação educativa, inserido na estrutura 
orgânica do centro bem como participando efetivamente, ou seja, estendendo sua atuação dentro do centro educativo e contribuindo para com a dinâmica do mesmo. Dessa forma este professor atua conjuntamente e de maneira colaborativa com os demais professores da escola a fim de "facilitar la interacción entre los profesores (tanto de educación ordinaria como de educación especial), los psicopedagogos y los logopedas, para que estudien y aporten soluciones a las dificultades del lenguaje de manera conjunta y coordinada" (ACOSTA y MORENO, 1999, p. 53) ${ }^{1}$.

Inserido neste âmbito, torna-se relevante apontarmos ainda o papel da formação profissional do professor de AL. Assumindo que ao longo desse processo - que abarca tanto a formação inicial como a permanente -, se constrói e reconstrói de forma integral o conjunto de competências profissionais do docente, através dos processos culturais vivenciados por este, de modo pessoal ou coletivo, se conclui a importância do âmbito formativo global na construção do pensamento profissional do professor de AL (LUQUE, 2013).

Segundo Gimeno (2009), a formação inicial que na atualidade recebe o professorado resulta insuficiente. As mudanças sociais ocorridas nas últimas décadas - as quais tem conduzido a uma sociedade globalizada, com acesso a numerosas e diversas fontes de informação e com constantes movimentos migratórios nas populações -, tem dado lugar a novos contextos educativos aos quais o professor deve estar à frente. Por isso, devido a este novo cenário, a formação acadêmica que recebe os futuros professores, em especial os de audição e linguagem, não costuma responder plenamente às necessidades que seu trabalho com os alunos irá apresentar.

No intuito de apontar novas possibilidades de discussão sobre o assunto para o âmbito acadêmico brasileiro, objetivamos nesta pesquisa caracterizar a prática pedagógica do professor de Audição e Linguagem no sistema educativo espanhol (Castilla-La Mancha).

\section{Metodologia}

Este estudo se constituiu numa pesquisa de caráter qualitativo, que de acordo com Bogdan e Biklen (1994, p.13) [...] "envolve a obtenção de dados descritivos, obtidos no contato direto do pesquisador com a situação estudada [...]".

\footnotetext{
1 Tradução da autora. "Facilitar a interação entre professores (tanto do ensino regular e educação especial), psicólogos educacionais e terapeutas da fala, para estudar e fornecer soluções para as dificuldades linguísticas de modo conjunto e coordenado" (ACOSTA e MORENO, 1999, p. 53).
} 
A pesquisa foi desenvolvida em um Centro de Educação Infantil e Primária (CEIP) ${ }^{2}$ da cidade de Guadalajara, província da Comunidade Autônoma de Castilla-La Mancha Espanha, chamado "Alvar Fañez de Minaya". Participou deste estudo a professora especialista de Audição e Linguagem deste centro. Os dados foram coletados por um período de dois meses com observações semanais junto a esta professora, que ora acontecia dentro da sala de aula e ora acontecia fora da sala de aula comum, isto é, em sua própria sala.

Neste sentido, utilizou-se a observação em sala de aula (comum e da professora AL), por ser de grande importância neste tipo de pesquisa como um meio facilitador da investigação acerca do assunto a ser abordado. De acordo com (Ludke \& André, 1986, p.26). "[...] a observação possibilita um contato pessoal e estreito do pesquisador com o fenômeno pesquisado, o que apresenta uma série de vantagens". Também foi realizada uma entrevista semiestruturada com esta professora versando sobre questões relacionadas ao apoio pedagógico que oferece aos alunos.

O desenvolvimento da pesquisa deu-se nas seguintes etapas: a primeira foi realizar um levantamento bibliográfico visando conhecer e caracterizar o trabalho deste professor; a segunda etapa consistiu-se da realização da entrevista com esta professora e a terceira se deu por meio de observação e anotação em diário de campo do trabalho desenvolvido pela mesma e por último, os dados obtidos foram organizados e categorizados.

\title{
Procedimentos de análise de dados
}

Os dados obtidos a partir das entrevistas e das observações foram analisados com base no referencial de Lüdke e André (1986). Segundo estas autoras:

\begin{abstract}
A tarefa de análise implica, num primeiro momento, a organização de todo material, dividindo-o em partes, relacionando essas partes e procurando identificar nele tendências e padrões relevantes. Num segundo momento essas tendências e padrões são reavaliados, buscando-se relações e inferências num nível de abstração mais elevado (LÜDKE; ANDRÉ, 1986, p. 45).
\end{abstract}

Este momento, segundo as mesmas autoras, se refere ao processo que vai "da análise para a teorização" (p. 49). Segundo as autoras já citadas a categorização não esgota a análise. É necessário que o pesquisador busque buscando realmente acrescentar

\footnotetext{
${ }^{2}$ Trata-se da Educação Primaria, a educação básica do sistema educativo espanhol, que compreende seis cursos acadêmicos.
} 
algo à discussão sobre o assunto proposto. Para isso, ele terá que estabelecer relações que possibilitem a proposição de novas explicações e interpretações.

Os dados a partir dos quais foram definidas as categorias principais, bem como seus pormenores, foram preferencialmente os obtidos com as entrevistas. A razão da escolha dos dados obtidos com este instrumento para a definição das categorias - em que se encaixam também os dados obtidos com as observações - foi principalmente a riqueza de assuntos abordados pelos participantes em suas respectivas falas.

\section{Resultados obtidos}

Caracterizamos a seguir (por meio das observações e entrevista realizadas) como é desenvolvido o trabalho da professora de Audição e Linguagem - AL, contextualizando a escola em que a pesquisa foi desenvolvida e analisando os dados, que foram abordados nas seguintes categorias:

\section{Caracterização do trabalho da professora}

Esta categoria visou contextualizar inicialmente a escola em que a pesquisa foi desenvolvida bem como caracterizar o trabalho desenvolvido pela professora.

O Colégio "Alvar Fañez" contava no ano da pesquisa (2015) com um total de 445 alunos, 30 professores, chamados de "tutores"- dentre estes, a professora de Audição e Linguagem -, 8 alunos diagnosticados com algum tipo de deficiência (motora, intelectual, visual e auditiva) e 20 alunos com dificuldades de aprendizagem.

A professora de $\mathrm{AL}$ atende um total de 15 alunos (todos possuem dificuldades ou transtornos específicos relacionados à linguagem), dentre eles encontram-se: alunos com deficiência auditiva (dois alunos oralizados e que utilizam apenas a língua oral e outro oralizado, porém que também utiliza a Língua de Sinais Espanhola), dificuldades articulatórias e/ou perceptivas, fonológicas e semântico-fonêmicas. A professora desenvolve seu trabalho com estes alunos em atendimentos - sessões - com duração de 45 minutos cada uma. Cada aluno tem 2 sessões (individuais ou em dupla) por semana com esta professora em sua própria sala (da $\mathrm{AL}$ ) e (de acordo com a necessidade de cada um e seu planejamento) dentro da sala de aula comum. A professora $A L$ atua em parceria com a professora regular, chamada de professora Tutora. 
Também realiza algumas atividades especificas de estimulação auditiva e linguística para favorecer a aquisição e o desenvolvimento da linguagem comunicativa no último curso da educação infantil ( 5 anos) em sala de aula comum (também uma sessão de 45 minutos).

Esta professora conta com uma pequena sala equipada com três mesas grandes com cadeiras, lousa, armário, computador, materiais didáticos como livros, jogos e programas de computador e um espelho grande junto a uma das mesas (para trabalhar atividades de reabilitações da base fonológica, onde o aluno se baseia na imitação e repetição de fonemas junto a professora). Conta também com variados jogos para o desenvolvimento da competência linguística e para o desenvolvimento de situações comunicativas de uso habitual, jogos simbólicos, jogos de sopro, jogos de computador, jogos de expressões e de palavras e jogos com imagens associadas a exercícios de articulação como o treinamento fonético e da fala.

A professora ressaltou por meio da entrevista realizada que são realizadas avaliações para identificar o grau de comprometimento comunicativo do aluno e assim, elaborar, orientada pela coordenação escolar, um planejamento e programa específicos. Dessa forma, a seguir, apontamos por meio de sua fala, a abordagem geral que trabalha com a maioria dos alunos.

\section{Formação docente}

Nesta categoria objetivamos contemplar a formação acadêmica e continuada da professora e dessa forma, destacar os aspectos encontrados. Há na realidade espanhola um "Consejo ${ }^{3}$ de Universidades" que em 1991, estabelece as diretrizes gerais dos planos de estudos (estrutura curricular) para a obtenção do título de professor de Audição e Linguagem. Este Conselho estabelece uma formação de três anos, que, na visão da professora AL entrevistada, é um curto período de tempo devido a toda especificidade que a profissão exige, e determina as matérias do tronco comum desta formação, organizadas em 180 créditos (um crédito corresponde a dez horas de ensino teórico ou prático). Destes, evidencia-se que $83 \%$ referem-se a componentes específicos de Audição e Linguagem e $17 \%$ a componentes educativos (ESPANHA, 1991). Com relação a parte pedagógica e a Língua de Sinais Espanhola a professora AL na entrevista aponta que:

As disciplinas pedagógicas são muito superficiais, não vi nada aprofundado.

Também a formação sobre Língua de Sinais na Universidade é bem restrita,

3 O "Consejo de Universidades" (Conselho de Universidades) é um órgão, vinculado ao Ministério da Educação, de coordenação acadêmica, cooperação, consulta e proposta em matéria universitária, composto pelos reitores das universidades. 
na verdade, é quase inexistente. Em minha formação tive 4 créditos de uma disciplina chamada "Sistemas alternativos de comunicação" e no planejamento dela tinha alguns conteúdos sobre os aspectos morfológicos e sintáticos dos distintos sistemas de sinais e de outros sistemas de comunicação (AL).

Neste sentido, vemos que apenas 3,23\% do número total de créditos das disciplinas de tronco comum são referentes a Sistemas alternativos de comunicação, e que inserida nesta disciplina encontram-se alguns apontamentos superficiais sobre a Língua de Sinais Espanhola. Algumas universidades oferecem disciplinas optativas que abordam a Língua de Sinais, porém também de forma sintetizada dentro de um tema mais geral. Por meio destes aportes verifica-se uma formação (relacionada à Língua de Sinais e ao âmbito pedagógico) insuficiente e deficitária, uma vez que o principal campo de atuação deste profissional é na escola.

Com relação a concepção de formação permanente, Gimeno (2009) adverte a conveniência de estabelecer reformas no sistema que se encarrega de seu desenvolvimento na atualidade, afirmando que "es necesario un cambio profundo en la metodología docente, en la orientación educativa, en la formación inicial y permanente del profesorado, en los currículos educativos y en los espacios y tiempos escolares" (p.52) ${ }^{4}$. Dessa forma evidencia-se que além de uma formação de qualidade, também são necessárias outras medidas que favorecem o atendimento destes alunos.

\section{Planejamento}

Por meio desta categoria pudemos observar como a professora AL realiza o planejamento de cada aluno. Cada aluno tem seu planejamento trimestral individual, realizado com base na adaptação do currículo de acordo com seu nível de competências linguísticas. Este planejamento é revisado pelo professor tutor, pelo orientador (quando necessário) ${ }^{5}$, e pelo professor PT.

O acompanhamento dos alunos é realizado em um diário, registrando observações como motivação, atitudes, habilidades trabalhadas, interações, assistências e pequenas observações dos tutores. A professora AL também registra os progressos realizados e/ou dificuldades encontradas periodicamente. Relata que "isto serve de base para oportunas modificações na programação e no horário individual de cada aluno" (AL).

\footnotetext{
4 "é necessário uma mudança profunda na metodologia docente, na orientação educativa, na formação inicial e permanente do professorado, nos currículos educativos e nos espaços e tempos escolares".

5 O Professor Tutor ou apenas Tutor é o professor encarregado de orientar a um grupo de alunos tanto individual como coletivamente. Os Orientadores atuam diretamente com o diretor do Centro escolar. Podemos aproximar sua função no contexto educacional brasileiro com a do coordenador escolar.
} 
Tal processo descrito anteriormente vai ao encontro das reflexões tecidas pelo autor espanhol Imbernón (2002) que enfatiza que o planejamento envolve a organização das ações em sala de aula e tal prática mostra uma dimensão da importância do ato de planejar, uma vez que o planejamento deve existir para facilitar o trabalho tanto do professor como do aluno, além de indicar as prioridades básicas e ordenar os recursos e meios necessários para a aprendizagem. Tais procedimentos quando pensados para um aluno em específico (neste caso os atendidos pelo professor $\mathrm{AL}$ ) expressam a individualidade de cada um e propiciam uma resposta educativa mais adequada a sua necessidade.

\section{Intervenção educativa}

A premissa básica para a intervenção realizada pelos professores AL é dar uma resposta adequada às necessidades educativas dos alunos no âmbito da linguagem e mais concretamente na linguagem oral. Isso implica a individualização da programação de cada aluno em função das características de cada um e da coordenação com os tutores. De forma geral, as capacidades e objetivos desenvolvidos pela professora AL entrevistada são: capacidades que favorecem a aquisição da linguagem (dentre elas a atenção e a percepção visual e auditiva) e a aquisição e desenvolvimento da linguagem (como por exemplo, o desenvolvimento morfossintático e o desenvolvimento léxico-semântico).

De acordo com a professora AL as estratégias de intervenção consistem em aumentar a frequência com que determinados objetivos linguísticos são apresentados ao aluno. Esta professora utiliza os seguintes procedimentos: "estratégias baseadas na imitação e em modelos, e na conversação, como em reformulações e ampliação de vocabulário. Em resumo, a competência oral compreensiva e expressiva se deve potenciar de forma pratica: a falar se aprende falando" (AL).

A mesma ressaltou que trabalha com diferentes etapas, como por exemplo, a etapa da discriminação e percepção auditiva, da identificação, do reconhecimento das palavras e da compreensão auditiva. Sobre a etapa de reconhecimento, ela relata que

\footnotetext{
Há uma etapa do reconhecimento onde se utilizam palavras e assim eles a compreendem e a expressam de maneira correta. Falamos palavras repetidas, as utilizando em frases e contextos fechados e abertos para que 0 aluno compreenda seu significado. Primeiro em classe de maneira fechada, em contexto fechado, apresento uma lâmina e logo vamos ao pátio ou em sua classe e vemos o som trabalhado e assim tento fazer com que o aluno me diga a mesma palavra em outro contexto (AL).
} 
Por meio de tais etapas e procedimentos, a professora AL visa contribuir para o desenvolvimento pleno dos alunos e assim estimular a comunicação entre eles em diversos contextos.

Tal prática desenvolvida por este professor corrobora com o apontado pela legislação espanhola, a qual define o trabalho do professor de Audição e Linguagem como aquele que contribui para promover competências linguísticas e desenvolver trabalhos e atividades relacionados aos problemas de linguagem, em específico à linguagem oral e escrita (ESPANHA, 1995).

Este trabalho educativo visa ainda desenvolver uma intervenção significativa, apontando mecanismos e estratégias que conduzam a oferecer uma resposta às necessidades educativas dos alunos em geral e as especiais em particular, favorecendo assim o processo de ensino e aprendizagem (ACOSTA e MORENO, 1999, p.53).

\section{Prática pedagógica e estratégias}

A professora em questão ressalta a importância de incidir na capacidade do aluno para usar a linguagem de forma significativa das seguintes maneiras: favorecendo a expressão oral com temas que estão vinculados a seus interesses; utilizando apoios gráficos e manipuláveis para motivar a comunicação e expressão, criando situações lúdicas; planejando situações comunicativas entre os interlocutores; aproveitando as competências leto escritoras para desenvolver capacidades vinculadas à linguagem oral como concordâncias e estruturação de frases e reforçando os progressos e esforços realizados, por menores que tenham sido, utilizando o reforço social.

$\mathrm{Na}$ entrevista realizada, a professora destacou que trabalha da seguinte maneira com os alunos:

Com relação ao sistema de comunicação com a linguagem oral, priorizo a funcionalidade da linguagem tanto comunicativa quanto social. Trabalhamos muito a consciência fonológica que é muito importante para a leitura e a escrita. As primeiras etapas da aprendizagem leitora das crianças, a decodificação e o vocabulário estão relacionadas com a compreensão leitora e por isso trabalhamos estas habilidades de várias maneiras $(A L)$.

A professora desenvolve atividades que permitem aumentar a autonomia dos alunos, priorizando o uso de técnicas e estratégias visuais bem como ampliar o léxico dos mesmos. Seleciona (em alguns momentos) os sons e os introduz em jogos variados de forma simples, buscando aprofundar conceitos aprendidos além de reforçar as respostas espontâneas dos alunos frente às situações que ela os coloca. 
Como a maioria dos alunos que atende possui dificuldades fonoarticulatórias e semântico-fonêmicas, apontou algumas práticas específicas que desenvolve com estes. Com os que possuem dificuldades fonoarticulatórias, primeiramente trabalha 0 desenvolvimento perceptivo da criança com atividades em que esta deve associar os sons e palavras a imagens alusivas, depois, a partir da leitura de suas próprias produções e com o apoio de imagens, deve identificar e localizar seus erros a fim de reconstrui-los. Com relação a associação de sons e palavras a imagens, distingue dois tipos de atividades: as orientadas a associação de sons não articulados (ruídos) e sons articulados com significado (palavras) com suas respectivas imagens e outras relacionadas a associação de sons articulados (palavras) pelo próprio aluno e previamente gravadas, a suas imagens correspondentes. Com os que possuem dificuldades fonológicas e semântico-fonêmicas, isto é, quando os erros ocorrem ao aluno produzir determinados sons em determinados contextos linguísticos e/ou semânticos, trabalha atividades individuais e em grupo. As atividades individuais são de acordo com o nível semântico e fonêmico em que o aluno se encontra e, para estas, são realizadas práticas fonoarticulatorias (como jogos com gargarejo e imitação do cacarejar da galinha) e atividades de contraste fonêmico (apoiadas na linguagem escrita) e fazendo relação com aspectos auditivo-vocais que são evidenciados durante a realização da mesma, e assim a professora apresenta tarjetas correspondentes as imagens com outras tarjetas de apoio com a escrita a fim de que a criança as coloque nos lugares adequados.

Segundo Roncato e Lacerda (2005), a capacidade de desenvolvimento de linguagem nas crianças é marcada pelas possibilidades de trocas verbais e discursivas e o adulto ou o professor tem uma função importante nesse processo no âmbito escolar, podendo promover uma série de atividades para essa evolução. Neste sentido, o professor mencionado desenvolve tais atividades e corrobora com tal evolução.

Estes autores ainda consideram a necessidade que as crianças têm de utilizar a fala por meio de experiências vivenciadas pelo uso da linguagem oral no cotidiano, não apenas em casa, mais também nas instituições escolares que é o lugar em que a criança passa a maior parte do dia, tendo contato com outras crianças e adultos. Dessa forma, o professor AL contribui com esse desenvolvimento utilizando as práticas mencionadas e promovendo tais experiências para o aluno com algum tipo de dificuldade relacionada à comunicação e a linguagem. 
Sobre o uso de recursos visuais e manipuláveis - como trabalhados pelo professor em questão - Reily (2003) aponta a importância da utilização de imagens visuais como recurso pedagógico para o ensino de crianças com algum tipo de dificuldade na área comunicativa, uma vez estabelecendo interações que enriquecem o processo de ensino e aprendizagem destes alunos possibilitando um desenvolvimento cognitivo mais significativo dos mesmos.

Tais apontamentos articulados as reflexões destes autores nos permitem apontar a relevância de práticas fonoarticularias e visuais no trabalho com alunos com dificuldades relacionadas à audição e a linguagem. Parceria

A professora AL ressaltou que trabalha em parceria com a professora de Pedagogia Terapêutica e com o orientador da escola por meio de reuniões semanais. Em relação à professora Tutora da sala comum estas reuniões também acontecem, ademais buscam estar sempre em contato, em especial quando esta vai buscar ou levar os alunos em sua sala e, assim, aproveitam para trocar algumas informações ou mesmo ter conhecimento daquilo que está sendo trabalhado por uma e outra.

Esta professora oferece aos professores Tutores, de forma geral, orientação e colaboração para a adaptação de determinadas tarefas a fim de facilitar a participação dos alunos que possuem alguma dificuldade, indicando materiais e atividades que fomentem a linguagem oral, bem como conselhos particulares sobre a melhor forma de se dirigirem a determinados alunos com dificuldades perceptivo-auditivas ou de processamento e compreensão. Reforça que:

Tem sido muito importante a coordenação com os tutores porque tem me dado a possibilidade de conhecer as características pessoais década aluno, realizar atividades conjuntas, compartir inquietudes e estratégias didáticas para melhorar a atividade docente, identificar conquistas e dificuldades durante o processo de ensino e aprendizagem (AL).

A legislação que aborda questões específicas relacionadas ao trabalho deste professor corrobora com o trabalho desenvolvido pelo mesmo, ou seja, tal professor deve

Colaborar con los otros profesores en la prevención, detección y valoración de dificultades del lenguaje y de aprendizaje (respectivamente), en las medidas de flexibilización organizativa, así como en la planificación y en el desarrollo de adaptaciones curriculares dirigidas a los alumnos con necesidades educativas especiales 0 bien a aquellos que presenten dificultades de aprendizaje (asociadas a la comunicación y el lenguaje oral o 
escrito, en el caso del maestro de audición y lenguaje) (CASTILLA-LA MANCHA, 2002, p.10878). ${ }^{6}$

Em vista disso, este professor juntamente com os demais professores e atores da escola desenvolve uma parceria colaborativa, em que para este processo os distintos profissionais encarregados de implementar uma resposta educativa concreta, definem, discutem e oferecem soluções aos problemas dos alunos de maneira compartilhada.

\section{Considerações Finais}

O presente estudo vislumbrou caracterizar o trabalho/apoio pedagógico do professor de Audição e Linguagem presente no sistema educativo espanhol, com o intuito de trazer possibilidades de discussão sobre este tema para o contexto acadêmico brasileiro.

Conhecer a realidade de outro país, em especial este que é considerado de referência por iniciar os trabalhos na educação especial, é importante para agregar informações e conhecer como outros países lidam com tal tema. Este conhecimento pode contribuir para com reflexões e diálogos para a realidade brasileira, a fim de melhorar as políticas e práticas de inclusão. Tendo em visto a análise tecida ao longo deste estudo, a partir dos instrumentos metodológicos utilizados foi possível observar a necessidade da reestruturação de determinadas práticas pedagógicas frente à inclusão a fim de favorecer a aprendizagem e a participação de alunos com deficiência, articulando estas a diferentes apoios dentro ou fora da sala de aula. Evidenciou-se desta forma, a importância e os aspectos positivos do trabalho do professor de Audição e linguagem para o processo de ensino e aprendizagem de alunos com dificuldades.

Salienta-se que a formação inicial deste professor se apresenta deficitária relacionada ao tocante da prática pedagógica e ao aprendizado da Língua de Sinais Espanhola, visto que são fatores significativos para seu trabalho na escola. Contudo, são apontados novos caminhos de formação permanente que partem do interesse dos professores e de suas experiências em sala de aula, reflexões estas também presentes no contexto brasileiro e que subsidiam a prática do professor.

Ressalta-se também a importância do trabalho realizado em parceria entre o professor

${ }^{6}$ Colaborar com os outros professores na prevenção, detecção e avaliação das dificuldades de linguagem e da aprendizagem (respectivamente), nas medidas de flexibilização organizativa, assim como na planificação e no desenvolvimento de adaptações curriculares dirigidas aos alunos com necessidades educativas especiais ou bem aqueles que apresentem dificuldades de aprendizagem (associadas à comunicação e a linguagem oral ou escrita, no caso do professor de Audição e Linguagem). 
$\mathrm{AL}$ e a equipe escolar a fim de promover efetivas situações de aprendizagem ao aluno, atuando assim de forma colaborativa e direcionado significativamente o trabalho a ser desenvolvido com os alunos com qualquer tipo dificuldade. Neste sentido tal interação possibilita avanços proeminentes também para o desenvolvimento dos alunos que são atendidos, uma vez que toda a equipe assume parte no planejamento e na intervenção junto ao alunado.

Destarte, a pesquisa buscou caracterizar o trabalho desenvolvido pelo professor AL, apontando novas possibilidades de atuação no contexto escolar, com alunos com algum tipo de comprometimento comunicativo e linguístico, mediante a tomada de atitudes e de estratégias diversificadas frente à educação inclusiva.

Portanto, por meio deste, evidenciou-se o papel do professor AL no desenvolvimento da aprendizagem destes alunos, ressaltando a importância da linguagem no processo de significação e apropriação do conhecimento por meio de metodologias pedagógicas que respeitem as limitações deste alunado e propiciem um ensino que seja promotor de emancipação para todos. Desta forma, evidencia-se que tais práticas também podem ser desenvolvidas no contexto brasileiro com alunos com estes comprometimentos.

Por fim, sublinha-se a pertinência e a necessidade de estudos que partem de outras realidades educacionais, a fim de propiciar reflexões e ações futuras para o contexto educacional brasileiro com o intuito de oferecer subsídios para diálogos que oportunizem diferentes práticas com estes alunos.

\section{Referências}

ACOSTA RODRIGUEZ, V.M. y MORENO SANTANA, A.M. Dificultades del habla infantil: un enfoque clínico. Investigación, teoría y práctica. Málaga: Aljibe, 1999.

BOGDAN, R. C. \& BIKLEN, S. K. Investigação qualitativa em educação. Porto: Porto Editora, 1994.

CASTILLA-LA MANCHA. Consejería de Educación, Cultura y Deporte. Resolución de 8 de julio de 2002. Disponível em:http://www.educa.jccm.es/educa$\mathrm{jccm} / \mathrm{cm} /$ educa_jccm/tkContent?idContent=14431\&locale=es_ES\&textOnly=false. Acesso em: 10 maio de 2015.

CASTILLA-LA MANCHA. Consejería de Educación, Cultura y Deporte. Resolución de 8 de julio de 2002. Disponíve em: 
http://www.educa.jccm.es/educajccm/cm/educa_jccm/tkContent?idContent=14431\&l ocale=es_ES\&textOnly=false. Acesso em: 10 maio de 2015.

ESPANHA. Ministerio de la Presidencia. Real Decreto 696/1995 de 28 de abril, de ordenación de la educación de los alumnos con necesidades educativas especiales. Disponível em: https://www.boe.es/boe/dias/1995/06/02/pdfs/A1617916185.pdf. Acesso em: 10 agosto 2015.

ESPANHA . Ministerio de la Presidencia. Real Decreto 1440/1991, de 30 de agosto, que establece el título universitario, oficial de Maestro, en sus diversas especialidades. Disponível em: https://www.boe.es/diario_boe/txt.php?id=BOE-A1991-24768. Acesso em: 30 julho 2015.

GIMENO, J.S et al. Educar por competencias, ¿qué hay de nuevo? Madrid: Morata. 2009.

IMBERNÓN, F. Del Proyecto Educativo a la Programación del Aula. Grao. Barcelona. 2002.

LÜDKE, M \& ANDRÉ, M. Pesquisa em Educação: Abordagens Qualitativas. São Paulo: EPU, 1986. p. 25-44.

LUQUE, A. \& CARRIÓN, J. El maestro de audición y lenguaje: formación, experiencia previa y acceso. Revista Electrónica Interuniversitaria de Formación del Profesorado, 16, 39-54. 2013.

Reily, L. H. As imagens: o lúdico no ensino de arte para Pré-escolares surdos. In: Gesueli (Org), Cidadania, Surdez e Linguagem: desafios e realidades. Cap. IX (pp.161-192), SP: Plexus Editora. 2003.

RONCATO, C. e LACERDA, C. Possibilidades de desenvolvimento de linguagem no espaço da Educação Infantil: Distúrbios da Comunicação, São Paulo, v.31, № 2, p. 215-223, ago. 2005.2 Disponível em: http://revistas.pucsp.br/index.php/dic/article/viewFile/11715/8439. Acesso em: 12 março. 2017.

\section{Correspondência}

Daiane Natalia Schiavon - Universidade Estadual Paulista. R. Quirino de Andrade, 215 - Centro, São Paulo. CEP: 01049-010. São Paulo, São Paulo, Brasil. http://orcid.org/0000-0002-1825-0097 


\section{(c) $($ i) (9)}

This work is licensed under a Creative Commons Attribution-NonCommercial 4.0 International (CC BY-NC 4.0) 